\title{
Colorectal Neuroendocrine Tumor pNX TNM Finding v8
}

National Cancer Institute

\section{Source}

National Cancer Institute. Colorectal Neuroendocrine Tumor pNX TNM Finding v8. NCI

Thesaurus. Code C135179.

Colorectal neuroendocrine tumor in which the regional lymph nodes cannot be assessed. (from AJCC 8th Ed.) 